\title{
Repeatability of the Questionnaire for the Aging Level Indices
}

\author{
Toshiyuki Ojima ${ }^{1}$, Izumi Oki ${ }^{1}$, Shinichi Tanihara ${ }^{1}$, Yosikazu Nakamura ${ }^{1}$, and Hiroshi Yanagawa ${ }^{2}$
}

The purpose of the study is to confirm repeatability of the series of self-administrating questions, which can be applied in large community populations. In 1994 and 1995, two surveys were conducted for the residents at Minamikawachi, Japan with a same questionnaire. The number of respondents for the both surveys was 887. Kappa statistics of all items of the series of questions for aging level indices were significantly high. Kappa statistics were over 0.4 , and repeatability is good or excellent in 28 items of all the 45 items. The statistics of the items for medical treatments of chronic diseases were high, in such as diabetes $(0.846)$ and hypertension (0.604). For activity of daily livings, such as shopping (0.619), kappa statistics were also high, but that of eating $(0.162)$ was low. The statistics of subjective symptoms were moderate, however, that of impairment of hearing (0.672) was high, and that of decline of interest in opposite sex (0.256) were low. On the other hand, kappa statistics of acute diseases were low, in such as bone fracture (0.073). Correlation coefficients of the comprehensive aging level indices are around 0.6 among the people of 65 years old or older. In conclusion, the repeatability of the questions and indices were good, and they are appropriate to apply to communities.

$J$ Epidemiol, $2000 ; 10: 321-327$

repeatability, self-administrating questionnaire, aging level indices, kappa statistics

\section{INTRODUCTION}

The life expectancy of human being has largely extended for these decades, but bedridden long life is in vain. We want to spend healthy and active life in old age. In reality we cannot completely avoid to have diseases, to feel complaint, and to be restricted for some activities in old age. Controlling aging progress is important to spend aged life without disabilities. In order to take actions to control aging progress, we need methods to measure aging progress.

Many studies have been conducted to measure aging progress using questionnaires about activity of daily livings (ADL) ${ }^{1-4)}$, physiological functions ${ }^{5,6)}$, physical fitness abilities ${ }^{n}$. Many of the studies dealt with one part of the aging, or were difficult to apply in large population.

We tried to inquire of medical treatment, subjective symptoms, and ADL in order to understand aging level. We have been making series of self-administrating questions, which can be applied in a large community population. Using the questionnaire, we already reported the results of the cross-sectional survey ${ }^{8)}$, the relationship between some items in the questionnaire ${ }^{9)}$, and comprehensive aging level indices ${ }^{10,11)}$. Although the questionnaire was useful to assess the aging level in general population, however, its repeatability of precision is still unclear. We conducted the same questionnaire survey twice with one year interval to observe the repeatability.

\section{METHODS}

We have conducted a cohort study from 1980 in Minamikawachi town, Tochigi, in Japan. The town is located in about $100 \mathrm{~km}$ north from Tokyo. The population is 19,844 , and the proportion of the people aged 65 years or more is $10.7 \%$ by the national census in 1995 . Most of the town is rural dis-

Received ; August 19, 1999 ; accepted April 7, 2000.

Department of Public Health, Jichi Medical School.

Saitama Prefectural University.

Address for correspondence: Toshiyuki Ojima, Department of Public Health, Jichi Medical School, Yakushiji 3311-1, Minamikawachi, Tochigi, 329-0498 Japan. 
trict, but a new housing town has been developed at the west part in this decade.

The first survey was conducted for all people over 19 years old except those living in the new town in June 1994. The questionnaires were distributed by mail, and collected by mail or by hand-to-hand at the place of mass screening.

Subsequently the second survey was conducted for all people over 63 years old from September through October 1995. The questionnaires were distributed and collected with cooperation from the leaders of the elderly people's clubs, chiefs of the neighborhood self-governing bodies, and social welfare association in the municipality. For both survey, the institutionalized people were included in the study population.

The series of the questions for the aging level indices were included in the questionnaire of both surveys. We requested to fill out by themselves. If a subject was not able to fulfill the questionnaire, we requested for his or her family to fill out. We informed the purpose of the study in the questionnaire, and only the people who consented to cooperate to the study answered the questionnaire.

We calculated kappa statistics ${ }^{12)}$ using the answer by the respondent to the both surveys. Moreover we calculated correlation coefficients between the two comprehensive aging level indices by the two surveys ${ }^{11)}$. These comprehensive aging level indices indicate living aging level. They can be calculated using linear equations from 5 items of questionnaire. The equations are different by sex and generations( less than 65 years old and 65 years or older ). The following items are used in plural equations: impairment of hearing, tendency to fall, going out, hypertension, and forgetfulness. We used SAS for the calculation.

\section{RESULTS}

The number of people who belonged to the target population for the both surveys was 1090 , who are 63 years old or older and who have participated in the cohort study from 1980. For the survey in 1994, the number of respondents was 933 (response rate was $85.6 \%$ ). For the survey in 1995, the number of respondents was 1020 (response rate was $82.9 \%$ ). The number of respondents for the both surveys was 887 .

Mean age ( standard deviation ) of the respondents for the both surveys was $72.1( \pm 6.73)$ years; besides, that of the nonrespondents at least for one of the surveys was $74.0( \pm 7.15)$ years old. Mean age of the non-respondents was significantly older $(p<0.01)$ than that of the respondents.

Repeatability of the questionnaire items for the aging level indices is shown in Table 1. The kappa statistics of all the 45 items were significantly higher than zero. For 28 items out of the 45 items, kappa statistics were 0.4 or more. The kappa statistic of medical treatment of diabetes was the highest $(0.846)$. For the items about medical treatment, the kappa statistics of medical treatment of hypertension $(0.604)$, heart disease
(0.602), gastric ulcer (0.534), cataract $(0.504)$, and prostatic hypertrophy (0.476) were high. The kappa statistics of the items about $\mathrm{ADL}$ also tended to be high, for example shopping (0.619), urination and evacuation (0.604). For the items about subjective symptoms, the kappa statistic about impairment of hearing was very high $(0.672)$.

For the rest 17 items, the kappa statistics were under 0.4 and comparatively low. The kappa statistic of medical treatment of bone fracture was the lowest $(0.073)$. The second lowest item was other treatments $(0.082)$. For the items about medical treatment, the kappa statistics of common cold $(0.228)$, liver disease $(0.286)$, and anemia $(0.300)$ were comparatively low. The kappa statistic about ADL for eating (0.162) was also low. For the items about subjective symptoms, the kappa statistics of decline of interest in opposite sex (0.256) and depressive feeling (0.332) were low. The kappa statistics of other items about subjective symptoms were between 0.3 and 0.5 except hearing loss and decline of interest in opposite sex.

The kappa statistics of the questionnaire items by sex and age groups are shown in Table 2. Kappa statistics for diabetes, impairment of hearing, and shopping ware significantly high in both sex and all the age groups. For many other questionnaire items kappa statistics are high even if in older age groups. Besides, the kappa statistics for common cold were low in most age groups. For bone fracture, other treatments, and eating, the kappa statistics were high in females, but those were low in males.

Furthermore, proportions of persons without missing answer are shown in Table 2. The proportions of persons who made no missing answer were decline in older age groups. About $10 \%$ of people made one missing answer, besides some people made more missing answers. The missing proportions were high for the following items: depressive feeling, dizziness when stand up, getting angry frequently, dysuria, and decline of interest in opposite sex. Besides, the missing proportions were low for the following items: bathing, dressing, eating, and urination and evacuation.

Correlation coefficients of the comprehensive aging level indices are shown in Table 3. For the equation about 65 years old and older, the correlation coefficients were around 0.6 and high. However, those of 75 years old or older were tend to be low. For the equation under 65 years old, the correlation coeffi-

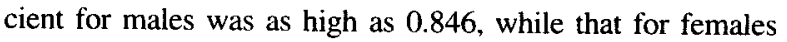
was 0.450 .

\section{DISCUSSION}

In this study, we observed the repeatability of aging indices using a self-administrating questionnaire form.

\section{Repeatability of each questions}

The kappa statistics of the all 45 items were significantly high. However, this is not enough to say that the repeatability 
Table 1. Repeatability of the Questionnaire Items for the Aging Level Indices.

\begin{tabular}{|c|c|c|c|c|c|c|c|c|}
\hline \multirow{2}{*}{ Questionnaire Items } & \multirow{2}{*}{$\begin{array}{l}\text { Medical } \\
\text { Treatment }\end{array}$} & \multirow{2}{*}{$\begin{array}{l}\text { subjective } \\
\text { Symptoms }\end{array}$} & \multirow[b]{2}{*}{$\mathrm{ADL}$} & \multicolumn{2}{|c|}{ Proportion of Positive } & \multirow{2}{*}{$\begin{array}{c}\text { Proportion } \\
\text { of Concordance }\end{array}$} & \multirow{2}{*}{$\begin{array}{l}\text { Expected Proportion } \\
\text { of Concordance }\end{array}$} & \multirow{2}{*}{$\kappa$ Staistics } \\
\hline & & & & 1994 & 1995 & & & \\
\hline Diabetes & $\bigcirc$ & & & $5.5 \%$ & $4.5 \%$ & $98.5 \%$ & $90.5 \%$ & $0.846 * *$ \\
\hline Impariment of Hearing & & O & & $49.9 \%$ & $54.6 \%$ & $83.6 \%$ & $50.0 \%$ & $0.672 * *$ \\
\hline Shoppinng & & & O & $9.1 \%$ & $11.6 \%$ & $92.9 \%$ & $81.4 \%$ & $0.619 * *$ \\
\hline Hypertension & 0 & & & $34.7 \%$ & $33.6 \%$ & $82.2 \%$ & $55.0 \%$ & $0.604 * *$ \\
\hline Urination and Evacuation & & & 0 & $1.0 \%$ & $1.8 \%$ & $98.9 \%$ & $97.2 \%$ & $0.604 * *$ \\
\hline Heart Disease & 0 & & & $8.6 \%$ & $9.1 \%$ & $93.6 \%$ & $83.9 \%$ & $0.602 * *$ \\
\hline Bathing & & & 0 & $1.7 \%$ & $3.3 \%$ & $97.9 \%$ & $95.2 \%$ & $0.576 * *$ \\
\hline Meal Preparation & & & 0 & $14.5 \%$ & $16.0 \%$ & $89.0 \%$ & $74.2 \%$ & $0.573 * *$ \\
\hline Dressing & & & $\bigcirc$ & $1.3 \%$ & $2.4 \%$ & $98.4 \%$ & $96.3 \%$ & $0.573 * *$ \\
\hline Withdrawal or Depositing Money & & & $\bigcirc$ & $14.4 \%$ & $16.2 \%$ & $88.6 \%$ & $74.1 \%$ & $0.562 * *$ \\
\hline Laundering & & & O & $9.7 \%$ & $13.2 \%$ & $91.0 \%$ & $79.6 \%$ & $0.559 * *$ \\
\hline Using Telephone & & & O & $5.7 \%$ & $6.7 \%$ & $94.7 \%$ & $88.4 \%$ & $0.543 * *$ \\
\hline Gastric Ulcer & $\bigcirc$ & & & $2.1 \%$ & $2.8 \%$ & $97.7 \%$ & $95.2 \%$ & $0.534 * *$ \\
\hline Putting Away the Bedclothes & & & $\bigcirc$ & $8.6 \%$ & $8.7 \%$ & $92.4 \%$ & $84.2 \%$ & $0.518 * *$ \\
\hline Keeping a Record of Household Account & & & ○ & $29.8 \%$ & $35.0 \%$ & $78.6 \%$ & $56.1 \%$ & $0.514 * *$ \\
\hline Cataract & 0 & & & $7.0 \%$ & $8.0 \%$ & $93.1 \%$ & $86.1 \%$ & $0.504 * *$ \\
\hline Cleaning & & & $\bigcirc$ & $8.8 \%$ & $9.9 \%$ & $91.5 \%$ & $83.1 \%$ & $0.497 * *$ \\
\hline Taking Bus, Train or Taxi & & & $\bigcirc$ & $18.5 \%$ & $16.8 \%$ & $85.3 \%$ & $70.9 \%$ & $0.496 * *$ \\
\hline Prostatic Hypertrophy & O & & & $1.9 \%$ & $2.3 \%$ & $97.9 \%$ & $95.9 \%$ & $0.476 * *$ \\
\hline Going Out & & & O & $6.5 \%$ & $8.1 \%$ & $92.6 \%$ & $86.5 \%$ & $0.457 * *$ \\
\hline Sleeplessness & & $\bigcirc$ & & $41.3 \%$ & $38.8 \%$ & $73.6 \%$ & $52.0 \%$ & $0.450 * *$ \\
\hline Tendency to Fall & & $\bigcirc$ & & $26.2 \%$ & $33.5 \%$ & $76.7 \%$ & $57.8 \%$ & $0.447 * *$ \\
\hline Prefer TV than Newspaper & & $\bigcirc$ & & $55.6 \%$ & $60.6 \%$ & $72.7 \%$ & $51.2 \%$ & $0.440 * *$ \\
\hline Diarrhea or Constipation & & 0 & & $16.8 \%$ & $22.3 \%$ & $82.1 \%$ & $68.4 \%$ & $0.434 * *$ \\
\hline Prefer Lying in the Leisure Time & & $\bigcirc$ & & $40.8 \%$ & $49.3 \%$ & $71.5 \%$ & $50.1 \%$ & $0.428 * *$ \\
\hline Dysuria & & 0 & & $13.1 \%$ & $14.4 \%$ & $86.0 \%$ & $76.3 \%$ & $0.411 * *$ \\
\hline Nocturnal Urine & & 0 & & $53.5 \%$ & $56.7 \%$ & $70.4 \%$ & $50.5 \%$ & $0.403 * *$ \\
\hline Easy to Feel Cold & & $\mathrm{O}$ & & $50.3 \%$ & $51.6 \%$ & $70.1 \%$ & $50.0 \%$ & $0.402 * *$ \\
\hline Payment & & & 0 & $6.2 \%$ & $6.8 \%$ & $92.7 \%$ & $87.9 \%$ & $0.396 * *$ \\
\hline Neuralgia & O & & & $5.3 \%$ & $5.3 \%$ & $93.9 \%$ & $90.0 \%$ & $0.393 * *$ \\
\hline Getting Angry Frequently & & O & & $15.5 \%$ & $18.9 \%$ & $82.7 \%$ & $71.4 \%$ & $0.393 * *$ \\
\hline Back or Joint Pain & 0 & & & $20.3 \%$ & $24.0 \%$ & $78.9 \%$ & $65.4 \%$ & $0.390 * *$ \\
\hline Dental Problem & & 0 & & $63.9 \%$ & $66.5 \%$ & $72.0 \%$ & $54.6 \%$ & $0.383 * *$ \\
\hline Decline of Visual Acuity & & 0 & & $68.4 \%$ & $71.0 \%$ & $73.5 \%$ & $57.7 \%$ & $0.373 * *$ \\
\hline Forgetfulness & & O & & $63.7 \%$ & $63.1 \%$ & $70.5 \%$ & $53.6 \%$ & $0.365 * *$ \\
\hline Dizziness when Stand Up & & $\mathrm{O}$ & & $13.9 \%$ & $16.9 \%$ & $83.1 \%$ & $73.9 \%$ & $0.354 * *$ \\
\hline Stroke & 0 & & & $1.7 \%$ & $1.5 \%$ & $98.0 \%$ & $96.9 \%$ & $0.347 * *$ \\
\hline Depressive Feeling & & 0 & & $14.8 \%$ & $19.1 \%$ & $81.1 \%$ & $71.8 \%$ & $0.332 * *$ \\
\hline Anemia & 0 & & & $1.8 \%$ & $1.8 \%$ & $97.5 \%$ & $96.5 \%$ & $0.300 * *$ \\
\hline Liver Disease & 0 & & & $1.8 \%$ & $1.2 \%$ & $97.9 \%$ & $97.0 \%$ & $0.286 * *$ \\
\hline Decline of Interest in Opposite Sex & & O & & $45.4 \%$ & $59.9 \%$ & $62.1 \%$ & $49.1 \%$ & $0.256 * *$ \\
\hline Common Cold & O & & & $16.7 \%$ & $17.2 \%$ & $78.2 \%$ & $71.8 \%$ & $0.228 * *$ \\
\hline Eating & & & 0 & $0.4 \%$ & $1.1 \%$ & $98.8 \%$ & $98.6 \%$ & $0.162 * *$ \\
\hline Other Treatments & 0 & & & $4.6 \%$ & $8.6 \%$ & $88.6 \%$ & $87.6 \%$ & $0.082 * *$ \\
\hline Bone Fracture & 0 & & & $2.3 \%$ & $2.5 \%$ & $95.7 \%$ & $95.4 \%$ & $0.073 *$ \\
\hline
\end{tabular}

According to $\kappa$ statistics $* *: \mathrm{p}<0.01 *: \mathrm{p}<0.05$ 
Table 2. $\kappa$ Statistics of the Questionnaire Items by Sex and Age Groups

\begin{tabular}{|c|c|c|c|c|c|c|c|c|c|}
\hline \multirow{2}{*}{ SEX and Age Group } & \multicolumn{4}{|c|}{ Male } & \multicolumn{5}{|c|}{ Female } \\
\hline & -64 y.o. & $65-69$ & $70-74$ & $75-$ & -64 y.o. & $65-69$ & $70-74$ & \multicolumn{2}{|c|}{$75-$} \\
\hline $\mathrm{n}$ & 33 & 93 & 71 & 104 & 64 & 178 & 160 & 184 & \\
\hline \multicolumn{10}{|c|}{ Proportions of persons without missing answer (\%) } \\
\hline no missing in 1994 & 72.7 & 60.2 & 59.2 & 50.0 & 56.3 & 62.9 & 55.6 & 52.2 & \\
\hline only one missing in 1994 & 0.0 & 11.8 & 7.0 & 12.5 & 9.4 & 12.4 & 13.1 & 9.2 & \\
\hline no missing in 1995 & 54.6 & 48.4 & 42.3 & 28.9 & 50.0 & 46.1 & 41.3 & 45.1 & \\
\hline only one missing in 1995 & 12.1 & 5.4 & 8.5 & 15.4 & 10.9 & 7.9 & 6.3 & 8.2 & \\
\hline \multicolumn{10}{|l|}{$\kappa$ Statistics by Questionnaire Items } \\
\hline Diabetes & $1.000 * *$ & $1.000 * *$ & $0.550 * *$ & $0.865 * *$ & $0.582 * *$ & $0.593 * *$ & $0.564 * *$ & 0.531 & $* *$ \\
\hline Impairment of Hearing & $0.900 * *$ & $0.835 * *$ & $0.533 * *$ & $0.608 * *$ & $0.881 * *$ & $0.704 * *$ & $0.920 * *$ & 0.903 & \\
\hline Shoppinng & $0.627 * *$ & $0.780 * *$ & $0.401 * *$ & $0.467 * *$ & $0.682 * *$ & $0.259 * *$ & $0.642 * *$ & 0.588 & \\
\hline Hypertension & $0.700 * *$ & $0.752 * *$ & $0.569 * *$ & $0.664 * *$ & $1.000 * *$ & ------ & $0.000 \mathrm{~ns}$ & 0.392 & $* *$ \\
\hline Urination and Evacuation & ------ & $0.000-$ & $1.000 * *$ & $0.000 \mathrm{~ns}$ & -..--- & $0.202 * *$ & $0.664 * *$ & 0.000 & ns \\
\hline Heart Disease & $0.784 * *$ & $0.631 * *$ & $0.722 * *$ & $0.514 * *$ & $0.000 \mathrm{~ns}$ & $0.664 * *$ & $0.391 * *$ & 0.392 & $* *$ \\
\hline Bathing & $1.000 * *$ & $0.000 \mathrm{~ns}$ & $0.653 * *$ & $0.523 * *$ & $0.083 \mathrm{~ns}$ & $0.338 * *$ & $0.448 * *$ & 0.271 & \\
\hline Meal Preparation & $0.651 * *$ & $0.526 * *$ & $0.437 * *$ & $0.415 * *$ & $0.547 * *$ & $0.259 * *$ & $0.415 * *$ & 0.421 & \\
\hline Dressing & $0.000 \mathrm{~ns}$ & $-0.016 \mathrm{~ns}$ & $1.000 * *$ & $0.581 * *$ & $0.308 * *$ & $0.179 * *$ & $0.202 * *$ & 0.317 & $* *$ \\
\hline Withdrawal or Depositing Money & $0.344 *$ & $0.778 * *$ & $0.351 * *$ & $0.505 * *$ & 0.000 & $-0.016 \mathrm{~ns}$ & $-0.022 \mathrm{~ns}$ & 0.198 & \\
\hline Laundering & $0.598 * *$ & $0.590 * *$ & $0.504 * *$ & $0.387 * *$ & -...- & $0.000 \mathrm{~ns}$ & $0.000 \mathrm{~ns}$ & $-\cdots----$ & \\
\hline Using Telephone & $0.650 * *$ & $0.411 * *$ & $0.639 * *$ & $0.613 * *$ & $1.000 * *$ & $0.415 * *$ & $0.339 * *$ & 0.503 & $* *$ \\
\hline Gastric Ulcer & $0.637 * *$ & $0.314 * *$ & $0.647 * *$ & $0.652 * *$ & -..--. & $-0.006 \mathrm{~ns}$ & $0.310 * *$ & 0.431 & $* *$ \\
\hline Putting Away the Bedclothes & $0.834 * *$ & $0.533 * *$ & $0.377 * *$ & $0.454 * *$ & $0.245 *$ & $0.167 *$ & $0.033 \mathrm{~ns}$ & 0.079 & ns \\
\hline Keeping a Record of Household Account & $0.420 *$ & $0.680 * *$ & $0.437 * *$ & $0.444 * *$ & $0.499 * *$ & $0.318 * *$ & $0.441 * *$ & 0.373 & $* *$ \\
\hline Cataract & $-----\cdot$ & $0.662 * *$ & $0.550 * *$ & $0.480 * *$ & $0.161 \mathrm{~ns}$ & $0.553 * *$ & $0.698 * *$ & 0.676 & $* *$ \\
\hline Cleaning & $0.469 * *$ & $0.575 * *$ & $0.332 * *$ & $0.318 * *$ & $0.499 * *$ & $0.358 * *$ & $0.440 * *$ & 0.206 & \\
\hline Taking Bus, Train or Taxi & $0.629 * *$ & $0.265 *$ & $0.496 * *$ & $0.594 * *$ & $-0.116 \mathrm{~ns}$ & $0.298^{* *}$ & $0.432 * *$ & 0.323 & \\
\hline Prostatic Hypertrophy & $1.000 * *$ & $0.479 * *$ & $0.000 \mathrm{~ns}$ & $0.492 * *$ & $0.296 *$ & $0.335 * *$ & $0.449 * *$ & 0.388 & $* *$ \\
\hline Going Out & $0.651 * *$ & $0.389 * *$ & $0.476 * *$ & $0.467 * *$ & $-0.029 \mathrm{~ns}$ & $0.321 * *$ & $-0.058 \mathrm{~ns}$ & 0.271 & $* *$ \\
\hline Sleeplessness & $0.238 \mathrm{~ns}$ & $0.485 * *$ & $0.478 * *$ & $0.279 *$ & $0.224 \mathrm{~ns}$ & $0.327 * *$ & $0.507 * *$ & 0.172 & ns \\
\hline Tendency to Fall & $0.000 \mathrm{~ns}$ & $0.631 * *$ & $0.374 * *$ & $0.579 * *$ & $0.174 \mathrm{~ns}$ & $0.437 * *$ & $0.452 * *$ & 0.227 & \\
\hline Prefer TV than Newspaper & $0.432 *$ & $0.441 * *$ & $0.596 * *$ & $0.327 * *$ & $0.170 \mathrm{~ns}$ & $0.158 \mathrm{~ns}$ & $0.459 * *$ & 0.325 & $* *$ \\
\hline Diarrhea or Constipation & $0.128 \mathrm{~ns}$ & $0.505 * *$ & $0.550 * *$ & $0.457 * *$ & $0.351 *$ & $0.213 *$ & $0.457 * *$ & 0.414 & $* *$ \\
\hline Prefer Lying in the Leisure Time & $0.335 \mathrm{~ns}$ & $0.407 * *$ & $0.336 *$ & $0.437 * *$ & $0.191 \mathrm{~ns}$ & $0.461 * *$ & $0.433 * *$ & 0.305 & $* *$ \\
\hline Dysuria & $0.128 \mathrm{~ns}$ & $0.695 * *$ & $0.652 * *$ & $0.479 * *$ & $0.525 * *$ & $0.352 * *$ & $0.401 * *$ & 0.389 & $* *$ \\
\hline Nocturnal Urine & 0.213 ns & $0.443 * *$ & $0.378 * *$ & $0.257 *$ & $0.141 \mathrm{~ns}$ & $0.393 * *$ & $0.240 *$ & 0.175 & $*$ \\
\hline Easy to Feel Cold & $0.394 *$ & $0.438 * *$ & $0.368 * *$ & $0.310 *$ & $0.647 * *$ & $0.378 * *$ & $0.549 * *$ & 0.404 & $* *$ \\
\hline Payment & $-0.042 \mathrm{~ns}$ & $0.210 *$ & $0.414 * *$ & $0.444 * *$ & $0.438 * *$ & $0.376 * *$ & $0.359 * *$ & 0.468 & $* *$ \\
\hline Neuralgia & $0.000 \mathrm{~ns}$ & $0.384 * *$ & $0.304 * *$ & $0.458 * *$ & $0.313 *$ & $0.495 * *$ & $0.499 * *$ & 0.318 & $* *$ \\
\hline Getting Angry Frequently & $0.224 \mathrm{~ns}$ & $0.459 * *$ & $0.735 * *$ & $0.372 * *$ & $1.000 * *$ & $0.744 * *$ & $0.688 * *$ & 0.605 & $* *$ \\
\hline Back or Joint Pain & $0.463 * *$ & $0.597 * *$ & $0.536 * *$ & $0.424 * *$ & $0.482 * *$ & $0.394 * *$ & $0.659 * *$ & 0.531 & $* *$ \\
\hline Dental Problem & $0.467 *$ & $0.508 * *$ & $0.276 *$ & $0.399 * *$ & $1.000 * *$ & $0.744 * *$ & $0.435 * *$ & 0.387 & $* *$ \\
\hline Decline of Visual Acuity & $0.077 \mathrm{~ns}$ & $0.263 *$ & $0.424 * *$ & $0.425 * *$ & $0.373 * *$ & $0.391 * *$ & $0.599 * *$ & 0.548 & $* *$ \\
\hline Forgetfulness & $0.472 * *$ & $0.555 * *$ & $0.104 \mathrm{~ns}$ & $0.286 * *$ & $0.659 * *$ & $0.391 * *$ & $0.659 * *$ & 0.344 & $* *$ \\
\hline Dizziness when Stand Up & $0.452 *$ & $0.652 * *$ & $0.144 \mathrm{~ns}$ & $0.133 \mathrm{~ns}$ & $1.000 * *$ & $-0.011 \mathrm{~ns}$ & $0.377 * *$ & 0.414 & $* *$ \\
\hline Stroke & -...-- & $0.314 * *$ & $-0.035 \mathrm{~ns}$ & $0.422 * *$ & $0.623 * *$ & $0.411 * *$ & $0.473 * *$ & 0.613 & $* *$ \\
\hline Depressive Feeling & $0.000 \mathrm{~ns}$ & $0.338 * *$ & $0.221 \mathrm{~ns}$ & $0.460 * *$ & $0.063 \mathrm{~ns}$ & $0.302 * *$ & $0.499 * *$ & 0.513 & $* *$ \\
\hline Anemia & $0.000 \mathrm{~ns}$ & $0.000 \mathrm{~ns}$ & $0.379 * *$ & $-0.010 \mathrm{~ns}$ & $0.000-$ & $0.000 \mathrm{~ns}$ & $0.275 * *$ & 0.606 & $* *$ \\
\hline Liver Disease & $-0.031 \mathrm{~ns}$ & $0.366 * *$ & $0.000 \mathrm{~ns}$ & --.- & $0.478 * *$ & $0.329 * *$ & $0.306 * *$ & 0.534 & \\
\hline Decline of Interest in Opposite Sex & $0.118 \mathrm{~ns}$ & $0.233 *$ & $0.302 *$ & $0.285 *$ & $1.000 * *$ & $1.000 * *$ & $0.664 * *$ & 0.347 & \\
\hline Common Cold & $0.358 *$ & $0.032 \mathrm{~ns}$ & $0.154 \mathrm{~ns}$ & $0.280 * *$ & $0.659 * *$ & ------- & $0.000 \mathrm{~ns}$ & $-0.009 \mathrm{l}$ & \\
\hline Eating & -...- & $0.000 \mathrm{~ns}$ & $0.000 \mathrm{~ns}$ & $0.000 \mathrm{~ns}$ & $1.000 * *$ & ------ & $1.000 * *$ & 0.278 & \\
\hline Other Treatments & $0.298 * *$ & $-0.074 \mathrm{~ns}$ & $0.068 \mathrm{~ns}$ & $0.080 \mathrm{~ns}$ & $1.000 * *$ & --- & $1.000 * *$ & 0.431 & \\
\hline Bone Fracture & -......- & $0.000 \mathrm{~ns}$ & $0.000-$ & $-0.026 \mathrm{~ns}$ & $0.792 * *$ & $-0.016 \mathrm{~ns}$ & $0.304 * *$ & 0.450 & \\
\hline
\end{tabular}

According to $\kappa$ statistics $* *: \mathrm{p}<0.01 \quad *: \mathrm{p}<0.05 \quad$ ns : not significant

Classified by age in 1994 
Table 3. Repeatability of the Comprehensive Aging Level Indices.

\begin{tabular}{|c|c|c|c|c|}
\hline & Age (year) & $\mathbf{n}$ & Correlatio & fficients ( $95 \% \mathrm{CI}$ ) \\
\hline \multirow{5}{*}{ Male } & $65-$ & 123 & 0.603 & $(0.476-0.704)$ \\
\hline & $65-69$ & 43 & 0.571 & $(0.327-0.744)$ \\
\hline & $\{70-74$ & 34 & 0.760 & $(0.567-0.873)$ \\
\hline & $75-$ & 46 & 0.561 & $(0.324-0.732)$ \\
\hline & -64 & 19 & 0.846 & $(0.636-0.939)$ \\
\hline \multirow{5}{*}{ Female } & $65-$ & 211 & 0.601 & $(0.507-0.681)$ \\
\hline & (65-69 & 79 & 0.714 & $(0.586-0.808)$ \\
\hline & $\{0-74$ & 61 & 0.633 & $(0.454-0.763)$ \\
\hline & $75-$ & 71 & 0.567 & $(0.384-0.706)$ \\
\hline & -64 & 31 & 0.450 & $(0.113-0.693)$ \\
\hline
\end{tabular}

Classified by age in 1994

$\mathrm{CI}$ : confidence interval

Correlation Coefficients are calculated from the Comprehensive

Aging Level Indices [11] using data in 1994 and those in 1995

The Comprehensive Aging Level Indices are calculated using each equation by sex and age group ( -64/65-)

is good. Landis et al. ${ }^{13)}$ provided the guidelines for the evaluation of kappa statistics. If the kappa statistics are over 0.75 , the repeatability is excellent. If the kappa statistics are between 0.4 and 0.75 , the repeatability is good. If the kappa statistics are lower than 0.4 , the repeatability is marginal. According to the guidelines, repeatability of diabetes was excellent in our study. The repeatability of 28 items out of the 45 items was good included diabetes. In addition, repeatability of all the 45 questions was marginal or better.

The repeatability of the items for medical treatment of diabetes and impairment of hearing was high. These items are about chronic status. Therefore, the results are reasonable. Other items such as medical treatment of hypertension, heart disease, cataract, and prostatic hypertrophy were also about chronic status. Then the high repeatability can be expected. The repeatability about medical treatment of gastric ulcer was also high. In general, active stage of gastric ulcer can be cured rapidly. However, many patients are thought to continue preventive treatment, because gastric ulcer can easily relapse. Repeatability about ADL was high. The reason may be because ADL change is not so often, and many people can answer the questions correctly.

The repeatability of medical treatment of bone fracture and common cold was low. These results are reasonable because we seldom continue treatment of bone fracture or common cold over one year. Repeatability of other treatment was also low. Many of the people who answered "yes" for this question were thought to have taken treatment for acute diseases. The repeatability of ADL for eating was low. The result was different from the report by Hachisuka et al., ${ }^{14)}$ in which the repeatability of eating ADL was very high. The difference may occur because the people who could not eat by themselves were very few in our survey. Therefore, the effect to kappa statistic of some persons whose eating ADL had changed during the one year period was large. If we conducted a survey in the population whose ADL were low, the repeatability of eating ADL would be higher. For the items about subjective symptoms, repeatability of decline of interest in opposite sex was low. The major reason of this result may be that the interest is hard to measure. Another reason is the interest to opposite sex can change rapidly with daily events. Domestic quarrel or encountering some persons by chance can change the answer to the question. One more possible reason is specialty in Japanese people. The Japanese tend to hesitate to express sexual issues frankly. Therefore, even if some people can answer honestly to the question about sex in some surveys, they may not answer frankly in another survey. The repeatability about depressive feeling was also low. The reason of this result may similar to that about decline of interest in opposite sex.

For the comprehensive aging level indices, the correlation coefficients between the two surveys was 0.6 and high in 65 years old or older. Under 65 years of age, the correlation coefficient for males was high and that for females was low. For people under 65 years of age, the number of samples who replied to both surveys was small. Consequently, the results under 65 years of age are not definite. Further researches will be needed for repeatability in younger generation.

\section{Reliability of the series of questions}

When we investigate aging level indices, we should consider repeatability of each item in a questionnaire. Besides, repeatability in this study comprises errors to answer the questions and changing actual state during one year between the two surveys. Therefore, the pure error to answer the questions is thought smaller than the results of this study. The all items of which repeatability is low in this study are not bad questions, because 
some of those items may sensitive to the changing actual state. If it is possible, we should investigate repeatability only for people whose actual state had not changed.

Sensitivity of the questionnaire items should also be investigated. For example, bone fracture are very important to prevent bedridden people. However, incidence cases of bone fracture are few for one year. We should conduct another survey some years later. Furthermore, we should inquire long-term medical histories.

We did not investigate internal consistency like Chronbach alpha coefficients ${ }^{15}$. This is because we wanted to measure comprehensive aging level using fewer questions. If the Chronbach alpha coefficients were high, we had considered that we should select fewer items.

\section{Validity of the series of the questions}

When we investigate validity, we should examine content validity, criterion validity, and construct validity ${ }^{16}$.

The research committee made much discussion to select items in the questionnaire to ensure high content validity. The number of items we selected is limited, because we wanted that the questionnaire could be used in large population without burdens. On the other hand, there are a number of questions in the many existing questionnaires. It is possible that some of the items in our questionnaire should be replaced to other questions. We should investigate more about content validity.

For criterion validity, there is no consensus about gold standard of aging, because each researcher has different understanding about aging. Thus, investigation about criterion validity is impossible nowadays.

For construct validity, the most typical index related to aging is calendar age. We already reported the obvious relationship between the answer to the questions and age ${ }^{8)}$ as well as the relationship between the comprehensive aging level indices and calendar age ${ }^{11)}$. Moreover, we reported relationship between the items about $\mathrm{ADL}$ and medical treatment of chronic diseases in the questionnaire ${ }^{9)}$. Thus, the construct validity of the questions is high. Nevertheless, we will be able to investigate other relationship with some data such as life expectancy. Utility of the aging level indices

This series of questions and comprehensive aging level indices can be used in order to measure aging level in a community. That is useful to the public health actions against avoidable aging.

Besides, we can measure aging level for individual residents and notice them the results. Persons whose aging level are younger than the actual age, will feel happy, and they will make more effort to keep youth. Persons whose aging level are older than the calendar age, will feel sad, but they can know which items of the questionnaire affects the results of older aging level, and they can make effort to control aging. On the other hand, it is problematic that some items can not be improved by a personal effort.

We regard that it is important to use the indices as an endpoint in epidemiologic studies. When we conduct a cohort study, we investigate lifestyles as a baseline survey. Afterward, we should investigate aging level as the endpoint. By the study like that, we will be able to clarify preventive factors not only against short life span or lower ADL but also against broader target about aging. When we reflect the purpose of the study like that, we should consider the structure of quality of life. Aging can be thought to be a part of the quality of life.

In conclusion, the series of questions and comprehensive aging level indices that we have proposed are good at repeatability. These results are essential to apply them to communities.

\section{ACKNOWLEDGMENTS}

We thank to the people who answered the survey, the social welfare association, and other community organization in the municipality.

This study was conducted as a part of the "Epidemiological Study about Aging, Using Existing Long Term Followed up Cohort" supported by the Longevity Science Comprehensive Research Project, Ministry of Health and Welfare, of the Japanese government.

\section{REFERENCES}

1. Mahoney FI, Barthel DW. Functional evaluation: the Barthel index. Md State Med J, 1965; 14:61-65.

2. Katz S, Ford AB, Moskowitz RW, et al. Studies of illness in the aged. The index of ADL: a standardized measure of biological and psychosocial function. JAMA, 1963; 185:914-919.

3. Lowton MP, Brody EM. Assessment of older people: Self-maintaining and instrumental activities of daily living. Gerontologist, 1969: 9:179-186.

4. Kim HS, So JM, Tanaka K. Assessment of the activities of daily living age in elderly women. Ann Physiol Anthrop, 1994; 13: 175-182.(in Japanese with English abstract)

5. Furukawa T, Inoue M, Kajiya F. Assessment of biological age by multiple regression analysis. J Gerontol, 1975; 30:422-34

6. Sasaki N, Kakigi S. Effects of aging on psychological and physiological function: Differences in tree test, GHQ (General Health Questionnaire), aspiration task, and cardiovascular parameters. Jpn J Psychol, 1998; 69:229234.(in Japanese with English abstract)

7. Nakamura E, Moritani T, Kanetaka A. Biological age versus physical fitness age. Eur J Appl Physiol, 1989; 58:778-785.

8. Yanagawa $\mathrm{H}$, Yashiro $\mathrm{M}$, Ojima $\mathrm{T}$, et al. Cross sectional 
survey about aging level in a community. Kosei No Sihyo, 1996; 43(2):3-8. (in Japanese)

9. Kishimoto M, Ojima T, Nakamura Y, et al. Relationship between the level of activities of daily living and chronic medical conditions among the elderly. J Epidemiol, 1998; 8:272-277.

10. Kishimoto M, Ojima T, Nakamura $Y$, et al. Building comprehensive aging level indices using multiple regression analysis for the aged living in community. Kosei No Sihyo, 1998; 45(11):27-34. (in Japanese)

11. Fujita Y, Kodama K, Kasagi F, et al. Building aging level indices based on ability to perform personal care and household management activities. Jpn J Hyg, 1999; 54:467-473. (in Japanese with English abstract)
12. Cohen J. A coefficient of agreement for nominal scales. Educ Psychol Meas, 1960; 20:37-46.

13. Landis JR, Koch GG. The measurement of observer agreement for categorical data. Biometrics, 1977; 33:159174.

14. Hachisuka K, Ogata H, Ohkuma H, Tanaka S, Dozono K. Test-retest and inter-method reliability of the self-rating Barthel Index. Clin Rehabil, 1997; 11:28-35.

15. Cronbach LJ, Furby L. How should we measure "change" - Or should we ? Psychol Bull, 1970; 74:68-80.

16. Fletcher RH, Fletcher SW, Wagner EH. Clinical epidemiology - the essentials second edition. Williams \& Wilkins, Baltimore, 1988: 22-23.

\section{Appendix. Questionnaire Form for the Aging Level Indices}

Q1. Have you taken the following medical treatments during last one year? ( please circle all items you have taken)

1.Hypertension 2.Diabetes 3.Heart Disease 4.Stroke 5.Liver Disease 6.Gastric Ulcer 7.Back or Joint Pain 8.Neuralgia 9.Common Cold 10.Bone Fracture

11.Prostatic Hypertrophy 12.Cataract 13.Anemia 14.Other Treatments(

Q2. Considering your condition now, please circle yes or no.

\begin{tabular}{lllll}
\hline 1.Decline of Visual Acuity & yes no & 9.Getting Angry Frequently & yes no \\
2.Impairment of Hearing & yes no & 10.Dizziness when Stand Up & yes no \\
3.Dental Problem & yes no & 11. Easy to Feel Cold & yes no \\
4.Tendency to Fall & yes no & 12.Diarrhea or Constipation & yes no \\
5.Nocturnal Urine & yes no & 13.Decline of Interest in Opposite Sex & yes no \\
6.Dysuria & yes no & 14.Sleeplessness & yes no \\
7.Depressive Feeling & yes no & 15.Prefer TV than Newspaper & yes no \\
8.Forgetfulness & yes no & 16.Prefer Lying in the Leisure Time & yes no \\
\hline
\end{tabular}

Q3. Can you do the followings yourself now? (please circle can or cannot) (If you can do but you don't do, please circle can)

\begin{tabular}{llll}
\hline 1.Shopping & can cannot & 6.Payment & can cannot \\
2.Cleaning & can cannot & 7.Withdrawal or Depositing Money can cannot \\
3.Putting Away the Bedclothes & can cannot & 8. Keeping a Record of Household Account can cannot \\
4.Meal Preparation & can cannot & 9.Using Telephone & can cannot \\
5.Laundering & can cannot & 10.Taking Bus, Train or Taxi & can cannot \\
\hline
\end{tabular}

Q4. Can you do the followings yourself now? (please circle can or cannot)

\begin{tabular}{llll}
\hline 1.Bathing & can cannot & 4.Urination and Evacuation & can cannot \\
2.Eating & can cannot & 5.Going Out & can cannot \\
3.Dressing & can cannot & & \\
\hline
\end{tabular}

